\title{
HIV/AIDS - A Social Context in Arunachal Pradesh (India)
}

\author{
Bikash Bage
}

\begin{abstract}
In this paper, the ways in which HIV is transmitted and factors facilitating transmission are described, although we still do not fully understand why the HIV epidemic has spread so heterogeneously across India. Estimates of HIV prevalence vary in quality but give some idea of trends in different countries and regions. Of all regions in the world, The North Eastern States and Arunachal Pradesh of India is the hardest hit by HIV, containing around $30 \%$ of people living with HIV/AIDS. There are, however, recent signs of hope in the states due to a slight reduction in the number of new HIV cases through government efforts.

Reductions in morbidity and mortality through the use of highly active antiretroviral therapy are at present limited to high-income and people near to facilities. Due to Topographical difficulties and communication bottleneck the nearest health facility is still a dream distance. There are visibility of both the cost of these therapies and the poor health care delivery systems in many affected areas of the region. The concept of Stigma and discrimination still persists, which are to be addressed before antiretroviral need can benefit the majority of people living with HIV/AIDS.
\end{abstract}

Index Terms-Arunachal Pradesh, discrimination, stigma, available services.

\section{INTRODUCTION}

HIV- Humane Immune Virus was a virus which rocked the humanity in1984 in USA. The first case of HIV was diagnosed to homosexual couples in a hospital in America. The world was shaken by the dangerous virus. Homosexuality was seen as a social taboo even in developed nation like the US. It is still unfortunate to understand that such stigmatization is prevalent in our communities.

Many scientists globally came up with theories of the origin of the deadly Virus, some say it came from the green monkeys of Africa among other theories. But the fact remained that the virus was amongst us, around us the people on this earth.

During those times homosexuals were treated as people who under quotes "are abnormal people" or "People who do not have good moral character" and the practice was not legalized, but today the struggle of homosexual has been achieved in terms of status of differently sexually oriented humans, where they are recognized and legalized to be married as couples. The evolvement has its own decades of struggle in the form of legalization of section 377 of IPC [1] in India by allowing Gay Marriage.

Manuscript received September 1, 2014; revised December 22, 2014 Bikash Bage is with the Dept. of Sociology, Rajiv Gandhi University, Rono Hills, Doimukh - 791112, Arunachal Pradesh, India (e-mail: bagebikash1@gmail.com).
Why should social factors affect HIV/AIDS epidemic is a question to be answered? The main reason is that HIV is transmitted through sexual activities which are not much talked about in our Indian society, the ill notions on the infection and drug-injection networks, which are fundamentally social phenomena, are not easily accepted and for that matter cared for in some of the parts of India.

India then was very proud in stating that HIV could never come in the communities as the society seemed extremely rigid and there could possibly be no such high risk behavioural activities prevalent. The government very proudly stated that HIV was disease of the western countries as they rated them to be related with immorality having promiscuous life with less moral values and tradition [2].

Whereas India was proud of its rich age old tradition of heritage, culture of family values and conservatism, but the fact was that in the year 1986 [3] the first case of HIV was diagnosed to a commercial sex worker in Chennai the then Madras in the state of Tamil Nadu. Unfortunately, India now poised to be one of the badly affected nations of HIV. In India about 2.39 million people are living with HIV (39\% females and $4.4 \%$ children below 15 years of age - NACO 2011). The estimated adult HIV prevalence is $0.31 \%$. In Asia, India accounts for $60 \%$ of HIV burden (UNAIDS 2010). About $55 \%$ of HIV burden is concentrated in five states of Andhra Pradesh, Maharashtra, Karnataka, Tamil Nadu and Manipur in NE India with proximity to Arunachal Pradesh. [4].

Manipur, with a population of only 2.4 million in the NE region of India, has the highest concentration of HIV infection in the country. It is one the leading states in the country with the highest number of HIV infected amongst youths due to the rapid increase of intravenous drug users. As per Manipur S t a t e AIDS Control Society (March, 2008), the epidemiological report stated that the number of HIV positive in sero-surveillance and sentinel surveillance were 23239 and 5,908 respectively. The number of AIDS cases was 4249 .

\section{TRANSMISSION OF INFECTION}

\section{A. Sexual Transmission}

- Accounts for over $75 \%$ of all cases

- Common among homosexual men

- Heterosexual transmission most rapid in female partners of male in drug abusers

- Male to female transmission higher in US and female to male in Africa and parts of Asia

- Enhanced by coexisting STDs (e.g., syphilis, chancroid, 
herpes etc.)

\section{B. Contaminated Blood Transmission}

- Drug abusers (largest group)

- Random recipients of blood transfusion

C. Mother-to-Infant Transmission

- In utero by transplacental spread

- Delivery through an infected birth canal

- After birth by ingestion of breast milk

\section{Occupational Transmission}

- Seen in health care workers, lab. worker

- Needle prick injury

- Risk increases with exposure to large volume of blood, prolonged contact, potential portal of entry, blood patients with advanced-stage disease.

\section{HIV AND ITS SOCIAL PERSPECTIVES}

HIV/AIDS continues to be major global health priority. The initial years of HIV/AIDS in India had evolved so many myths and misconceptions. It was highly stigmatized and people infected with the disease were discriminated not only by the common people but by the medical practitioners too. Stigma exists in variety of ways, including ostracism, rejection, discrimination and avoidance of PLHA, mandatory testing without prior consent or protection of confidentiality, violence against HIV infected or people who are perceived to be HIV infected and the quarantine of such individuals, stigma related violence or fear of violence preventing people from seeking test and counseling or securing treatment, possibly turning what could be a manageable chronic illness into a death sentence and perpetuating the spread of HIV[5]. Some believed that the Virus originated in women and passed on to the man. Women in traditional Indian society had a very low social status and with the coming of HIV/AIDS these women were infected and affected severely. Misconceptions remained so deep-rooted that some sections of the society believed that sleeping with young virgin girl could kill the virus in an infected man. Women, girls and children remained as one of the most vulnerable sections till date.

The social determinants of health as discussed above are the circumstances in which people are born, grow up, live, work, and age, as well as the systems put in place to deal with illness. These circumstances are in turn shaped by a wider set of forces: economics, social policies, and politics. As of HIV and its social epidemiology, social norms about appropriate choice, numbers and timing of partners and about behaviours with those partners shape crucial network variables such as concurrent sexual and injection partnerships, partner turnover rates, mixing patterns, the size, centrality and microstructures of community network components and the extent of risks such as group sex parties, bath-houses, and shooting galleries. Social norms, regulations, educational systems and law enforcement processes affect sexual and drug-taking behaviours. On the other hand social networks, norms and social support shape how people access, interpret the HIV related issues and use HIV-prevention information and education, the extent to which people make use of sexually transmitted disease treatments and HIV therapies, HIV counseling and testing, and affect adherence to therapies.

In India, national programs like National AIDS Control Organization, under Ministry of Health \& Family Welfare, have taken up various programmes to control and disseminate knowledge on the deadly HIV/AIDS to every nook and corner of the country.

\section{EPidemiological Situation in ARUnachal Pradesh}

In Arunachal Pradesh the first case of HIV/AIDS was detected in the year 1998, when Arunachal Pradesh was itself horrified by the growing rise of the deadly virus in the neighboring north eastern state like Manipur. As of October 2014 there are 244 HIV sero positives detected so far in the state. The prevalence in Arunachal as per last HIV surveillance is $0.16 \%$. Only 1 district, namely Lohit fall in A-category. Arunachal Pradesh is showing rising trends in adult HIV prevalence as observed between 2006 and 2012.

Based on available HIV estimates of 2011 by NACO, Arunachal Pradesh is estimated to have at least 1156 PLHA.

With the Intervention of the national programmes with the current theme of "Zero Infection" and "halting the further infections", many projects were undertaken to curb the growing rise of HIV Virus. Although efforts have been made by the government, NGOs and Community based organizations, but till now HIV/ AIDS is in the rise in Arunachal Pradesh.

TABLE I: PRESENT STATUS OF HIV/AIDS

\begin{tabular}{|l|l|}
\hline Epidemic Scenario (2014 Estimates) & Total \\
\hline No. of PLHA estimated & 1156 \\
\hline No. of HIV positives detected & 244 \\
\hline No. of AIDS related deaths & 42 \\
\hline
\end{tabular}

Source: SIMS, monitoring \& evaluation unit, APSACS, Naharlagun, India [6].

\section{AIDS CASES Rising In ARUNACHAL PRADESh DESPITE MEASURES TAKEN}

Despite all possible measures adopted by the Arunachal Pradesh government and central agencies to create awareness among the masses, killer AIDS has spread its tentacles in the State over the past decade with 244 numbers of HIV positive cases detected out of about 2,73,000 clients screened till October 2014 [6].

India has the world's third-largest population suffering from HIV/AIDS according to the United Nations 2011 AIDS report and since the year 1998, the number of cases in Arunachal Pradesh is showing an increasing trend.

During 1998 when Arunachal Pradesh AIDS ControlSociety (APSACS) was first introduced, only two HIV positive cases were reported in the entire State. However, the figure shot up to 167 till 2010 with many unreported cases in the State. Figures from various districts Integrated Counselling and Testing Centers (ICTCs) [8] are also awaited by the Society.

"Awareness is the only visible vaccine available against the killer disease with the number of positive cases 
increasing in leaps and bound with every passing day,"

The government is making all-out efforts to create awareness and educate the people on the disease and to take proper care. Our people are still lagging behind in implementing their knowledge and keeping themselves safe. Unless people are aware, no efforts of waging war against AIDS will bear fruit.

According to a recent survey report prepared by National AIDS Control Organization (NACO), the estimated cases of AIDS in the State is 1156 and that the number of positive cases in the State could go higher as the figures available with the APSACS are the record of people who voluntarily come for testing only. It cannot be ruled out the possibility of much more number of AIDS patients in the State as many cases still going unreported.

The APSACS has been conducting regular programmes like Information Education Communication (IEC) for creating awareness among the masses. It has also been engaged in Targeted Intervention (TI) that takes on high risk groups including commercial sex workers, intravenous drug users (IVD Users), truck drivers and migrant labourers through

The number of HIV positive cases is increasing only as a result of more and more people being detected by the various ICTC set up in the districts. During the earlier years, lesser numbers of cases were detected because of fewer numbers of ICTCs in the State.

However, out of the detected cases in the State which is increasing, cases are registered in the lone Anti Retroviral Therapy (ART) Centre, while the remaining cases have not been registered due to ignorance about the fatality of the disease. ART Centre provides free therapy for the patients. With the setting up of the Community Care Centre where, doctors and nurses are being trained for the Models of counseling [9] of the AIDS patients besides establishment of four linking ART, it is hoped that more positive people would be tapped in near future.

Casual approach of people towards AIDS in Arunachal Pradesh has resulted in a 100 fold jump in HIV positive cases in the last 14 years even though the state government has made efforts to create awareness about it [10].

The government and APSACS are contemplating to start testing at primary health centres and community health centres in the state for people who cannot afford to travel to the district headquarters for being tested for the disease. Increasing number of adult HIV cases during the period of last four years in Arunachal Pradesh is a great matter of concern.

The rising trend of HIV cases during 2006-2009 in the state is a great challenge which could be contained with all out efforts from each and every section of the society. The theme of the this year's advocacy programme is' getting to zero, zero new HIV infection, zero discrimination and zero AIDS-related deaths' and this theme has to be implemented in toto to achieve our desired goals.

However AIDS as a leading illness is still on the rise. India has responded to HIV/AIDS by shaping strategic response to the HIV epidemic through NACO by taking up innumerable steps; focusing on issues like involving NGOs, addressing issues and challenges pertaining to the needs and reaching to the mass and educating etc.[11].

The future holds on one of the main concern in India and especially in the state of Arunachal Pradesh that is on the full range of costs and consequences likely to result from several plausible policy choices regarding government funding and locating of antiretroviral therapy facilities [12].

It helps policymakers make decisions by:

- Reviewing the state of the epidemic and of treatment in India.

- Reviewing the effects and consequences of antiretroviral therapy.

- Using an epidemiological model to predict the course of the epidemic, including its consequences and costs, under current government policies.

- Using the same model to determine the consequences and costs of alternative policies and compare their effects with the consequences and costs of maintaining current policies.

In this regard it is a concern that social change in Arunachal Pradesh is likely to create complex problems for our response to HIV.

There is a high probability of massive political, ecological and social changes over the next few years. These concepts threaten large-scale disruption of existing social and risk networks, sexual (and injection) mixing patterns, and sexual and injection behaviours that can impede or facilitate HIV transmission - and thus might generate HIV outbreaks. We have to think ahead 10 years or more so we will be prepared to meet the challenges that will face us. Over this next decade, many formidable challenges are likely to stem from the interactions of social, ecological, political, and economic change; existing social structures; the changing HIV epidemic, and changes produced by emerging biomedicine and viral evolution. Although some challenges will be unpredictable, we should plan ahead for those we are able to anticipate.

It can be argued that a balance has to be made between responding the present and future needs in the health system. Sustainability of health service delivery requires recognition of longer term perspectives. It is about continuity of section for health and services that contribute to meeting the goals of health system. However, sustainability is not an absolute value in itself. Some actions and services should not be sustained as health needs and forms of intervention need to respond to change. Unfortunately, bureaucratic inertia and vested interests can lead to the contribution of unnecessary organizations and services [13].

"People are still very casual in approach to the disease, "Unless people are aware, no effort of waging war against AIDS will bear fruit,"

A number of macro-level and mid-level social factors shape HIV transmission and care by affecting risk networks, behaviours, and the degree of sexually transmitted infections and HIV treatment and care are on. Social processes such as wars and transitions, as well as the interactions among emerging biomedicine, rates of disease outcomes, viral evolution, and the social reactions to these, need to be studied so we can anticipate and reduce the devastation that AIDS creates. The relative lack of this kind of research has weakened the response - both individual and societal - to the 
epidemic.

\section{REFERENCES}

[1] Section 377 of Indian Penal Code, The free Encyclopedia, Article from Wikipedia.

[2] B. Ambati, J. Ambati, and A. Rao, Dynamics of Knowledge and Attitudes about AIDS among the Educated in Southern India, AIDS Care, vol. 9, no. 3, pp. 319-330, 1997.

[3] S. P. Falleiro, Economic Impact of HIV/AIDS on Households, New Delhi, India, SAGE Publications India Pvt Ltd, 2014, p. 2.

[4] J. P. Narain, Three Decades of HIV AIDS in ASIA, SAGE pub. Pvt. Ltd, New Delhi, 2012, pp. 107-108.

[5] A. K. Lobiyal, Status of HIV/AIDS in India, New Delhi, India, Cyber Tech Pubs., 2008, p. 25.

[6] SIMS, "Monitoring \& evaluation unit," Arunachal Pradesh SACS, Naharlagun, India.

[7] National AIDS Control Organization (NACO) (1999), "India responds to HIV/AIDS: A strategic response to the HIV epidemic by the government of India, the UN, and its development partners in India," NACO, Ministry of Health and Family Welfare, Government of India, New Delhi, 1999-2000.

[8] National AIDS Control Organization (NACO) FAQ on Integrated Counseling and Testing Centres. NACO, Ministry of Health and Family Welfare, Government of India, New Delhi.

[9] A. K. Yadav, HIV/AIDS Problems, Causes and Control, Cybertech Pubs. New Delhi, India, 2007, p. 153.

[10] Arunachal Pradesh State AIDS Control Society, Naharlagun, Arunachal Pradesh on the occasion of WORLD AIDS DAY 2013.

[11] National AIDS Control Organization (NACO) (2012), "India responds to HIV/AIDS: A strategic response to the HIV epidemic by the government of India, the UN, and its development partners in India," NACO, Ministry of Health and Family Welfare, Government of India, New Delhi, 1999-2000.
[12] M. Over, P. Heywood, J. Gold, I. Gupta, and S. Hira, "HIV/AIDS treatment and prevention in India, modeling the costs and consequences," Elliot Marseille Human Development Network Health, Nutrition, and Population Series, The International Bank for Reconstruction and Development / the World Bank 1818 H Street, NW Washington, DC, 2004.

[13] C. Collins and A. Green, Valuing Health Systems, a Framework Foe Low and Middle Income Countries, SAGE pub. Pvt. Ltd, New Delhi 2014, p. 303

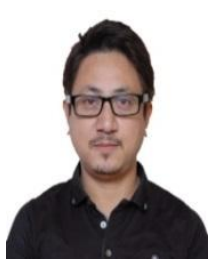

Bikash Bage was born on February 6, 1976. He has obtained his graduation degree in sociology 1996 from St. Edmunds College, Shillong and Post-graduation in sociology 1998 from North Eastern Hill University Shillong India. He qualified in National Eligibility Test (NET) and received Junior Research Fellowship (JRF) conducted by University Grant Commission, New-Delhi. In addition to it he has a degree of MBA in HR \& hospital, health management (IIBM, Meerut, India) and a degree in law (RGU, India). Mr. Bikash Bage served as a lecturer in sociology for three years at Don Bosco, College, Itanagar, Arunachal Pradesh and currently serves as an assistant professor in the Department of Sociology at Rajiv Gandhi Central University, Arunachal Pradesh, India. He has participated in many national and international conferences and has published several research papers in journals of national and international repute.

$\mathrm{He}$ has also served as a senior programme officer under National AIDS Control Organization, Ministry of Health and Family Welfare, New-Delhi (GOI) in Arunachal Pradesh from 2001 to 2010. He has vast experience in the field of health. His interests and publications are in the fields of sociology of health, environmental sociology, gender studies, tribal studies, sustainable development and community mobilization. 